\title{
CRIANÇA E MENOR NA SOCIEDADE BRASILEIRA: SERVIÇOS, CUIDADOS E EXCLUSÃO
}

\author{
Fabíola Zioni Gornes * \\ Rubens de C. Ferreira Adorno *
}

ZIONI GOMES, F. \& ADORNO, R. C. F. Criança e Menor na Sociedade Brasileira: serviços, cuidados e exclusão. R. B. C. D. H. 1(1); São Paulo, 1991.

\section{RESUMO}

Discutem-se as condições para emergência e desenvolvimento de programas de saúde infant $^{\wedge} \mathrm{h}$. Discorre-se sobre o conceito de criança, saúde e serviços de saúde prevalente em determinados períodos históricos, assim como suas relações com interesses políticoeconômicos dominantes nessas conjunturas, considerando-se os aspectos sociais do conhecimento. Reflete-se sobre a questão criançax menor na sociedade brasileira.

\section{INTRODUÇÃO}

Para se discutir o crescimento e desenvolvimento, enquanto prática de saúde pública, é necessário fazer alguns comentários sobre como se estruturam os serviços de saúde sobre o caráter social de sua formação.

Já se pode considerar como clara entre os profissionais e estudiosos da área a existência de uma estreita relação entre saúde e sociedade, tanto no sentido da maneira como os homens vivem ser geradora da temática de saúde, como no sentido de que as intervenções sobre ela são produzidas a partir das relaçỗes sociais.

Na identificação de problemas, na definição de suas causas, na elaboração de medidas terapêuticas ou preventivas e na definição de prazos e prioridades, outros elementos, além daqueles oriundos do conhecimento científico ou de normas racionais de conduta, são determinantes.
Entende-se por serviço de saúde o exercício legitimado da Medicina, Odontologia e outras práticas de saúde pública, cujo fim explícito é preservar e restaurar a saúde da população (Singer) ${ }^{1}$. Para o autor desta definição, os serviços de saude relacionam-se desde sua origem com a própria evolução do capitalismo industrial.

A revolução industrial - avanço tecnológico aplicado ao campo da produção - levou à substituição do trabalhador individual, manufatureiro e proprietário de seus instrumentos de trabalho, por unidades de produção baseadas no pleno aproveitamento da máquina e arregimentação de quantidades cada vez maiores de mão-de-obra.

Nesse sentido, os serviços de saúde nascem e se desenvolvem com o intuito de produzir condições materiais e ideológicas indispensáveis ao desenrolar da vida política, social e económica em determinados moldes. Assim, para cada conjuntura econômico-social de um país produz-se

\footnotetext{
* Sociólogos, mestres em Saúde Publica, docentes do Departamento de Prática de Saúde Pública da Faculdade de Saúde Pública da USP e membros do Centro de Pesquisa Social em Saúde da Faculdade de Saúde Pública da USP.

1 SINGER, P. et. al. Prevenir e Curar: o controle social através dos serviçosde saúde. Rio de Janeiro, Forense Universitária, 1979.
} 
uma organização dos serviços de saúde, adequada às necessidades de manter e reproduzir a força de trabalho e garantir a preservação dessa estrutura.

Se a organização dos serviços de saúde é influenciada pela sociedade como um todo, é do conhecimento científico que ela vai tirar normas para sua atuação.

Vale lembrar que, se a ciência, entendida como um dos componentes do conhecimento humano, não pode ser considerada como desvinculada do momento histórico em que se dá esse conhecimento, assim ela também, a exemplo dos serviços de saúde, será afetada em sua organização e avanço por outras instancias que não as do pensamento e reflexão. mas:

Considerando-se, portanto, os dois proble-

a. Características históricas, portanto, político-ideológicas dos serviços de saúde; e

b. Complexidade dos fenómenos a serem tratados por eles (processo saúde-doença, processo crescimento-desenvolvimento, por exemplo), infere-se que o acompanhamento e controle deste último processo, em nível de políticas públicas e de programas específicos para o setor saúde, dificilmente poderá ser executado com desenvoltura suficiente.

A complexidade das questões do crescimento e desenvolvimento pode ser considerada consensual entre os autores e profissionais da área.

No que se refere aos serviços de saúde, muitos elementos poderiam ser escolhidos para discussão. Selecionou-se, porém, uma questão específica, ou seja, comentar-se-á, no presente trabalho, como a criança é entendida pelos serviços de saúde e como esta compreensão é orientada pela conjuntura politico-social, conferindo às propostas técnico-cientfficas um conteúdo politicoideológico.

Escolheu-se este tema em função de se ter notado - já há algum tempo - um certo esvaziamento do debate político em torno da questão da saúde.

O debate sobre a determinação social do processo saúdedoença, sobre 0 direito à saúde como uma questão política e de extensão da cidadania, a tomada da questão da saúde pelos movimentos sociais urbanos constituíram traços importantes do setor ao longo dos anos 70 . Terminariam, porém, por serem absorvidos institucionalmente tanto em nível internacional (Alma-Ata, 1978) ${ }^{2}$ como em nível nacional, principalmente depois da transição negociada.

No entanto, o debate acabou por se concentrar principalmente na organização de um Sistema Nacional de Saúde com as características necessárias para maior extensão e cobertura da população, fazendo com que problemas que extrapolam a assistência médica sejam tratados secundariamente.

Assim, discutir "crescimento e desenvolvimento" como um problema a ser assumido pelo setor saúde, dentro de uma perspectiva mais ampla do que o acompanhamento antropométrico e a prevenção de doenças, pode ser oportuno no sentido de contribuir para a elaboração de um novo conceito de saúde e de saúde pública, para novas propostas práticas e políticas para o setor.

Para colaborar com este debate, acreditase importante esclarecer como, em determinados momentos históricos, a sociedade refletiu sobre a criança e como esta reflexão se traduziu em termos de práticas sociais e/ou institucionais.

\section{A CRIANCA: DO DESCOBRIMENTO A RUPTURA DO PACTO COLONIAL}

Até o século XIX não se registraram intervenções sistemáticas sobre a saúde da criança. No entanto, não deixaram de ocorrer reflexões e práticas sobre ela, que diziam respeito ao tipo de conjuntura social em que eram elaboradas.

O período colonial por ser polarizado socialmente permite mostrar mais claramente esta relação. Em termos gerais, o colonialismo pode ser entendido pelas palavras de Novais ${ }^{3}$.

\begin{abstract}
Escravismo, tráfico negreiro, formas várias de servidão formam portanto o eixo em torno do qual se estrutura a vida econôrnica e social do mundo ultramarino. A estrutura agrária fundada no latifúndio se vincula ao escravismo e através dele às linhas gerais do sistema; as grandes inversões exigidas pela produção só encontram rentabilidade, efetivamente, se organizadas em grandes empresas.
\end{abstract}

Em síntese, a estrutura fundamental dos sistemas de colonização se traduzia em: latifúndio, escravidão e monocultura.

Esse tipo de organização social engendrava um padrão de relações sociais caracterizado

2 CONFERÊNCIA INTERNACIONAL SOBRE CUIDADOS PRIMÁRIOS DE SAUDE. Alma-Ata, URSS, 1978. Relatório. Brasília,Unicef, 1979.

3 NOVAIS, F. A. O Brasil nos quadros do antigo sistema colonial. In: Mota, C. R., org. Brasd em Perspectiva. São Paulo, Difel, 1976, pp. 47-63. 
pelo autoritarismo e descomprornisso social que, além de marcar toda a época colonial e diversas fases da História do Brasil, constitui, ainda hoje, um padrão significativo.

No que diz respeito à assistência médica; o Brasil-Colônia não registrava trabalhadores livres em número suficiente para justificar medidas de atendimento médico ou de saúde pública.

No Brasil, a grande massa de trabalhadores era constituída por escravos—considerados legalmente co» coisas de propriedade do senhor rural. Não competia ao poder colonial zelar pela sua saude.

A escassa população pobre, não-escrava, valia-se de assim tência filantrópico e religiosa

Para as tropas militares existia a figura do Cirurgião-Mor que superintendia o exercício da cirurgia e dos hospitais militares. Ao Ffsico-Mor ou a seus delegados competia a supervisão do exercício da farmácia, da medicina, de curandeiros e de práticas de saneamento das cidades.

A questão da saúde, envolvendo uma preocupação com a assistência médica ou com a higiene das cidades, era subalterno ou inexistente; os problemas de higiene eram de responsabilidade das autoridades locais, que se limitavam a impedir a proliferação da imundície nas ruas e nos quintais.

Até meados do século XVIII a questão da saúde só se colocava a partir da simples percepção da relação entre "sujeira/ cidade/doença", o que poderia prejudicar o comércio de produtos coloniais.

No entanto, desde o século XVI, as nações européias centrais colocavam-se diante da questão da produtividade económica, que era entendida como relacionada à existência de uma população numerosa, crescente, sadia e plenamente empregada.

Essa preocupação com a população não foi transportada para o Brasil, por vários motivos. Em primeiro lugar, pelo falo de essas preocupações terem sido mais bem registradas na Alemanha, Inglaterra e França do que nos estados peninsulares. Em segundo lugar, a economia colonial organizava-se de forma suplementar à metrópole. Esta deveria ser rica às expensas da colónia, que deveria produzir com um mínimo de investimento. Vale lembrar, ainda, que a mão-de-obra nas colónias era escrava, o que não justificava medidas de controle de saúde.

Nesse contexto explica-se a inexistência de uma política para crianças e/ou para o conjunto da população. A concepção de criança na colónia fica bem exemplificada pelo texto a seguir:

Oh! Como estou feliz que morreu meu filho. Quando eu morrer cinco criancinhas (estarão) a me rodear Entra! Mamãe! (no paraíso)...

Observando que essa reação era bastante comum na colónia, um viajante europeu assim se manifestou:

Não posso ter uma opinião boa sobre o futuro de um lugar onde assim se dissolvem os mais fortes laços dos seres deste mundo (Costa) ${ }^{4}$.

Esta concepção de criança correspondia à forma de organização social engendrada pelo sistema colonial.

Assim como o indivíduo adulto não existia socialmente fora dos limites da propriedade rural (ou de sua extensão citadina), a criança sé era vista como um elemento posto a serviço do poder paterno. Para a família, cujo "epicentro" repousava na figura paterna, a criança/filho sé poderia receber uma atenção genérica. Até o século XIX, a infancia não foi tematizada, nem pela família nem pelo Estado4.

Este ponto pode ser explicado pelo falo de a estrutura social da Colônia ser polarizada entre proprietárias e não-proprietários. A sobrevivência estava ligada à conquista e posse da propriedade, processo esse extremamente violento e dependente, em boa medida, da energia e capacidade do adulto-pai, cuja figura não poderia ser desgastada, sequer em termos de desvio de atenções e/ou perda de prestígio.

Para reforçar essa concepção de criança, a tradição cat61ica concorria com a imagem de criança como ser purificado, sem mácula, um "anjo". Toda a preocupação iconográfica da época era coberta pela figura dos "anjinhos", cuja morte não seria motivo de dor, conforme dizia a canção: "Feliz anjinho que vai pro céu"4.

Essa tradição (que parece ter sido aproveitada pelos jesuítas para compensar a alta mortalidade de crianças indígenas na época) pode ter contribuído significativamente para que a vida biológico-moral da criança não fosse valorizada. 4 Segundo Costa4:

Na colônia a representação social da criança monopolizava o sentido de sua vida, os papéis culturais de "filho incapaz" e de "anjinho" superpunham-se e obscureciam sua condição de etapa biológico-moral no desenvolvimento do adulto... Entre o adulto e a criança, as ligações

4 COSTA, J. F. Ordem Médica e Norma Familiar. Rio de Janeiro, Graal, 1979. 
existentes eram as de propriedade e da religião. Um fosso as separava. Os elos que uniriam a cadeia das gerações só foram criados quando a família dispôs de representações da criança como matriz fisico-emocional do adulto... Esta recodif,cação da imagem da criança deveu-se em grande parte à reação dos higienistas.

Para o autor, a concepção colonial sobre família, crianças e mulheres fez com que até o século XIX não se registrasse preocupacão com o crescimento e o desenvolvimento da criança. A criança como filho, elemento secundário da casa senhorial, não merecia maior destaque.

A família - ao contrário da visão ideal de família burguesa - não estava centrada no cuidado da prole: mesmo em nível de valores e princípios, explícitos ou não, a família baseava-se na manutenção do patrimônio.

Neste contexto, as relações pessoais e de afetividade não apareciam como centrais. O caráter das relações era dado pelo predomínio do pai, do adulto.

A partir de 1700, a estrutura social começou a apresentar algumas brechas. Esss mudanças advinham da atividade mineradora, que requeria elementos livres, tanto da escravidão como da propriedade rural e uma administração centralizada para controlar a produção^j o que leva ao desenvolvimento dos primitivos núcleos urbanos.

No bojo dessas mudanças começavam a surgir um novo elemento que seria a possibilidade de desenvolvimento do trabalho livre, cujo locas não seria o mundo da propriedade rural mas aquele da cidade colonial.

Pressupondo-se que a saúde pública aparece para atender questões que podem constituir barreiras ao desenvolvimento económico, sua emergência no Brasil esteve relacionada à necessidade de controle do ambiente urbano, tanto no contexto das relações dos homens com o meio físico como no contexto das relações sociais que eram desenroladas dentro das condições ditadas pelo modo de vida urbano, e deste urbano colonial com a Metrópole.

Principalmente a partir do século XVIII, com o surto da expansão urbana, a estratégia de dominação da Metrópole passou a enfatizar a segurança da cidade. Entre as várias estratégias elaboradas pelo Estado—militarização da população, controle urbano/sanitário, e outras - uma das que mais se destacou foi a questão da higienizarão da família.

Entende-se por higienização da família o processo relacionado à implantação de uma visão de mundo para o conjunto da sociedade, visão essa necessária à manutenção do poder da Coroa Portuguesa (Estado), que fora relativamente contestado pelas elites coloniais, cujos interesses não mais coincidiam diretamente com aqueles das classes dominantes portuguesas.

Além disso, essas elites impunham às cidades - locas do poder metropolitano - uma lógica da propriedade rural, dado que a cidade era vista como extensão dessa propriedade.

Ao trazer para a cidade o padrão de ocupação do espaço e das relações sociais do mundo rural, eram essas elites as grandes responsáveis pelo caos urbano que tanto ameaçava a colónia “... a anatomia urbana da Colônia mostra como a casa, ocupando todo o lote, delimitava a rua, o privado impunha se ao público que desembocava no desrespeito aos locais públicos, no descumprimento das normas de limpeza" (Costa) $)^{5}$.

O controle espacial pelas famílias proprietárias era reforcado pelo monopólio do poder. Apesar de amparar-se na própria legislacão municipal portuguesa, esse poder não correspondia mais às expectativas do Estado português.

Em primeiro lugar, já não existia uma correspondência automática entre os interesses do latifúndio e da Metrópole. Em segundo, nos dizeres de Costa ${ }^{5}$, "a família não formava cidadãos e sim parentes... a participação dos indivíduos nas sociedades resumia-se à defesa do grupo a que pertenciam... Donde a oposição que o Estado sofria quando os convocava para o cumprimento das tarefas nacionais...”.

Não satisfeita em criar uma elite autocentrada e dependente do pai e do clã, a família colonial pretendia impor-se como modelo para o conjunto da sociedade: “... na medida em que dominava o meio urbano reduzia as outras camadas sociais a seu modo de ser...”.

Esse padrão de comportamento em relação ao público precisou ser quebrado pela Coroa para manter a cidade livre da sujeira — que, pela criação de doenças, perturbava as atividades comerciais - e da invasão de outras potências européias.

Para responder a essas contradições, o Estado, entre outras estratégias, passou a intervir por meio da criação de uma visão de mundo que compatibilizasse as elites agrárias com seu projeto de dominação. Esta questão fica clara quando se analisa o discurso higienista que se afirmava, a partir do século XVIII, refletindo essa articulação entre Medicina, saúde e sociedade em termos da criação de condições superestruturais (ideológicas e políticas) para manutenção da ordem.

4 COSTA, J. F. Op. cit. 
O papel ideológico da Medicina, no sentido de moldar comportamentos compatíveis com o projeto económico vigente, era desenvolvido, naquele momento, em relação às famílias da elite agrária, mas não se prendia à necessidade de resolver contra dições dadas em nível da estrutura de produção, mas à necessidade de adequar a tradição colonial dessas elites às novas exig ncias económicas e políticas advindas com o fim do pacto colonial e com as transformações que vinham ocorrendo na estrutura social brasileira. Esse processo exigiu uma ofensiva ideolo; gica que foi travada principalmente pela estratégia higienista, cujo alvo principal foi a reestruturação familiar, conforme a análise de $\operatorname{Costa}^{\wedge} \mathrm{S}$. A reestruturação do núcleo familiar, por sua vez, implicava na mudança da concepção desenvolvida tradicionalmente sobre a criança.

Os cuidados gerais que a criança recebera durante todo o período colonial foram substituidos - pela ação da higiene e da puericultura — por uma assistência sistematizada quanto a condutas alimentares, disciplinares, pedagógicas e mesmo de vestuário. Para desempenhar esses cuidados, a família precisava redefinir o papel do pai e da mãe; precisava, principalmente, organizar-se em novos moldes.

Essa nova forma de organização familiar e o objetivo pelo qual ela passaria a se pautar (procriar e educar crianças sadias para a Nação carente de uma população forte e produtiva) eram compatíveis com a nova ordem que se pretendia instaurar a partir do século XIX: não mais uma Colônia voltada para interesses em ternos, não mais uma agregação de propriedades rurais regidas por Interesses locais, mas uma Nação Independente, voltada para a produção e acumulação de capital.

Identificando o interesse do Estado com o interesse nacional e ambos a uma conduta entendida como "natural” e, portanto, desejável, a higiene passava a descrever o tipo de família e de educação necessários para a criação de um adulto identificado com a Nação/Estado.

Para Costa $^{5}$ "a medicina social percebia que 0 processo de urbanização forçava a mudança da farn lia e que o Estado, apoiando a expansão da saúde pública, lhe havia creditado uma certa confiança que competia explorar até onde fosse possível...”. Citando autores da época, o autor afirma que a higiene era concebida como

a parte da ciência médica que nos dá os preceitos e as regras necessárias tanto à aquisi-

\begin{abstract}
ção como à conservação da saúde e se referem a exercícios, banhos, sono, paixões, trabalhos intelectuais, enfim, ensina a evitar as coisas nocivas e fazer um bom uso das coisas úteis. Nada mais coerente com esta definição que a ingerência médica em todos os selares de vida pública e privada... Esse cuidado... tinha objetivos explícitos, dos quais o mais importante era a proteção das mulheres e crianças...
\end{abstract}

No entanto - ainda que obedecendo a uma racionalidade científica mais avançada do que os paradigmas anteriores - a higiene e a medicina da época também estavam impregnadas pelo caráter social do conhecimento do qual nenhuma disciplina científica pode ser considerada isenta.

Nesse sentido, saúde em geral e a saúde da criança em particular começavam a se confirmar não só co» um campo de intervenção técnica, mas como um campo de normatizaçao da vida cotidiana, de acentuado caráter ideológico.

Pelas publicacões próprias e intenso debate teórico, os higienistas desenvolviam concepções sobre as relações Medicina/saúde e Estado que-a exemplo das propostas de hifenização da família - eram imbuidos de conteúdo ideológico. Conforme Machado e col. ${ }^{6}$ :

Para que se preserve a saúde de uma população, portanto, há necessidade de implantação de uma sociedade onde não se suscitem paixóes, onde reine a ordem, onde tudo funcione... A medicina, conhecendo o homem e as alterações de seu organismo provocadas pela desordem, deve guiar o processo de estabelecimento e o funcionamento desta sociedade... Oferece o saber do corpo, que deve ser disseminado por toda a sociedade - fazendo com que cada um evite a paixão e a desordem - e que deve ser a base do funcionamento do corpo social... Temperança, contingência, moderação nos costumes, tranquilidade da alma - virtudes que se opõem à turbulência e desordem em defesa da vida, virtude cujo exercício é relacionado a uma sociedade que o permite, que o funde.

Viu-se, até aqui, como a concepção de criança esteve relacionada aos problemas que a sociedade colonial tinha que administrar.

\section{A CRIANÇA: DA CAFEICULTURA AO PROJETO INDUSTRIAL}

No final do séxulo XIX, nas primeiras décadas do século XX, era outro o projeto dominante na sociedade brasileira. 
A sociedade e o Estado viam-se às voltas com a criação e manutenção de condições para o desenvolvimento da cafeicullura; setor hegemônico na economia, o café consolidava no Estado uma oligarquia rural, para a qual a questão social era um "caso de polícia”.

A saúde pública era entendida ou praticada como forma de garantir a produção e o escoamento do café. Daí as políticas de saneamento de portos e cidades próximas à cultura do café e/ou de combate às doenças que dificultassem a imigração (febre amarela, varíola).

Acompanhando o processo de expansão do café, registravam-se a expansão urbana, o crescimento populacional, as atividades comerciais e a crescente complexidade da sociedade brasileira.

Junto com os braços para o café vieram as idéias anarquistas que contribuíram para convulsionar o pafs. Em 1917, ocorria a maior greve do período. A Nação parava. O Estado, que reagia de maneira repressiva, foi, pouco a pouco, obrigado a mudar a concepção do problema social.

É nesse contexto que surgiram preocupações mais sistematizadas com assistência às crianças, ainda marcadas, porém, por um conteúdo de controle social e decorrentes da necessidade de investir sobre a força de trabalho ou sobre as relações capitaltraba $\wedge^{\wedge} \mathrm{l}^{\wedge} \mathrm{o}$. Surgiram, também, os primeiros passas para a criação dos serviços de saúde.

Em termos de serviços de saúde, datam de 1920 as primeiras preocupações com 0 atendimento à criança, via serviço de higiene infantil; datavam também dessa época a regulamentação da licença à gestante e à puérpera (30 dias para cada uma das situações) e a proibição do trabalho fabril para menores de 12 anos. A morta^1idade infantil e a necessidade de atender a criança foram discutidas no Segundo Congresso Brasileiro de Proteção à Infância7.

Esses fatos mostram a emergência da questão das condições de vida e da saúde da criança no contexto da questão social, que Já se configurava como problema do Estado Nacional ainda que com vestígios de "questão de polícia".

A preocupação com a higiene infantil inspirava-se no modo lo médico-sanitário baseado na filosofia de saúde pública adorada nos EUA desde o século anterior. Essa filosofia era voltada para o atendimento da população imigrante carente (dos EUA), com ações de enfermagem domiciliária, prevenção de tuberculose, tratamento de doenças venéreas e atendimento rnaterno-infantil pelos Centros de Saúde e de Educação Sa- nitária, que visavam, de modo especial, a higiene individual, pré-natal, infantil e escolar, aprovoeitando a oportunidade apresentada pela infancia para a implantação de hábitos sadios ${ }^{8}$.

Registrava-se, nessa época, o aparecimento concomitante da educação sanitária e da higiene infantil, ambas com a mesma orientação filosófica, que centrava no comportamento do indivíduo as raízes de seus problemas, sem refletir sobre as suas condições concretas de existência, sobre o saber popular elaborado a respeito dos temas de saúde e sobre a estratégia de vida elaborada pelas camadas populares diante das pressões do cotidiano.

A transmissão de informações sobre higiene extrapolava a sua racionalidade interna à medida que englobavam afirmações sobre comportamentos desejáveis do ponto de vista moral e que pretendiam desenvolver uma consciência cívica nacional, guardando uma semelhança temática com as propostas dos séculos XVIII e $\mathrm{X} 1 \mathrm{X}$ em relação às elites da época, ainda que revestidas de maior "cientificidade" e orientadas para moldar o comportamento das classes populares urbanas agitadas pelos movimentos sociais dos anos 20, pelas crises econôrnicas e pela fragilidade das políticas sociais que começavam a se desenvolver.

A proposta da educação sanitária justificava-se em termos de sua própria eficiência e lógica interna em relação à aquisição de saúde. Se não dava a idéia de uma identificação total entre higiene e moral, não deixava de relacionar conotações moralistas e de propostas patrióticas ao comportamento esperado em saúde. Traziam também mensagens de conteúdo racista que não destoavam do ideário e de paradigmas científicos da época.

Essas afirmações são ingeridas a partir da leitura de documentos e discursos da época. $\mathrm{Na}$ sessão inaugural do Segundo Congresso Brasileiro de Higiene ${ }^{2}$, realizado em 1928, os congressistas manifestaram sua preocupação com a "torrente imigratória”, com a "vaga nipónica” que, pela mistura das raças, poderia provocar o desaparecimento do "brasileiro vigoroso, rijo e capaz, consciente e culto" e convocou a saúde pública, pela ação de "enfermeiras visitadoras", para promover a educação nacional em tríplice aspecto físico, intelectual e moral, que promoveriam a "higienização das massas”.

Resumindo, a saúde infantil, que emergia com as demais práticas sanitárias no bojo do processo de expansão capitalista, apesar de já se arti-

7 CONGRESSO BRASILEIRO DE HIGIENE, 2 ${ }^{\circ}$, Rio de Janeiro, 1928. Anais. Rio de Janeiro, 1928.

8 ROCHA, S. M. M. Puericultura e Enfermagem. São Paulo, Cortez Ed., 1987. 
cular em termos de serviços de saúde e de utilizar algumas “armas” terapêuticas científicas, como vacinas, assistência pré-natal e puericultura, mantinha seu caráter ideológico quanto à constituição de uma visão de mundo adequada às elites dirigentes e assumia um papel cada vez mais importante nessa estratégia de controle, conforme relata Costa ${ }^{9}$ :

\begin{abstract}
Durante os Congressos Brasileiros de Higiene, a questão da saúde infantil despertaria grande atenção. [No entanto]... o objeto da reflexão não foi a condição de vida e o trabalho da infancia operária, como apareceu em alguns pontos da legislação sanitário. A reflexão... tendeu a privilegiar as disposições da educação moralizadora e domesticadora. Ou seja, os sanitaristas elegeram a criança como alvo de intervenção pedagógica objetivando hábitos e atitudes da população frente à doença... A criança... seria o primeiro estágio da prática educacional em saúde cuja finalidade última seria atingir os padrões sanitários familiares.
\end{abstract}

Não obstante seu caráter ideológico, as políticas públicas que diziam respeito às crianças representavam um avanço sobre suas anteriores condições de vida e atenderam, de um lado, às exigências de preservar a força de trabalho e de regular as re lações capital-trabalho e, de outro, às exigências do próprio trio vimento operário, conforme colocações de Costa ${ }^{9}$.

Essas diretrizes não foram alteradas ao longo de todo o penado histórico compreendido pelo Estado Novo (1937) e o Golpe de Estado de 1964 mesmo durante o breve período de democracia formal, populista, compreendido entre o pós-guerra e 1964. A criança foi !:ematizada ao longo desse período como uma peça na estratégia de poder por parte dos selares dominantes que, de um lado, precisavam criar um tipo de população afinada com os objetivos da sociedade e, de outro, precisavam garantir a reprodução da força de trabalho sem desviar recursos do projeto de industrialização. Engendrou-se, assim, uma política social de caráter restrito que se traduziu, em termos de saúde, pela baixa cobertura e atuação normativa e discursiva.

Em nível do discurso, o Estado assumiu desde 1937 a responsabilidade pela saúde infantil. A saúde, por sua vez, era entendida a partir de características positivas e não como simples ausência de doenças. No entanto, segundo Novaes ${ }^{10}$, não se rãgistrou nenhum efeito prático:

\begin{abstract}
Ainda era grave a realidade:... a mortalidade infantil ainda se apresenta em liiveis bastante elevados, existe elevado grau de desorganização administrativa... a medicina, supondose que ela tenha papel a cumprir no controle das doenças, ainda está desarmada, não tem os antibióticos e as vacinas.
\end{abstract}

As preocupações para com a criança, dentro do setor saúde, no entanto, independentemente de sua racionalidade interna, guardavam relações com propostas normativas de épocas anteriores (como as propostas higienicistas para a família), com a diferença de que eram voltadas para a criação de padrões adequados de comportamento junto às classes trabalhadoras, uma vez que a divergência entre as classes proprietárias rurais e o Estado havia se tornado secundário ou inexistente diante do desenvolvimento urbanoindustrial e o aparecimento de outras contradições.

Administrar relações conflituosas entre setores sociais, via atendimento de demandas e criação/difusão de ideologia/visões sociais de mundo, que justificassem a ordem reinante, foi um dos componentes da intervenção do Estado junto ao grupo infantil até o momento da ruptura do Estado Populista, nos meados da década de 60.

Até 1964 as propostas para os grupos que se constituíam no interior do setor saúde, além de apresentarem essas características ideológicas, desenvolviam-se principalmente junto ao subsetor saúde pública que, a partir da década de SO, passou paulatinamente para um lugar secundário com as preocupações de expansão do -atendimento médico via Previdência Social, expansão essa voltada para a mão-de-obra urbano-industrial.

A emergência de programas para crianças ${ }^{11}$ que se deu em meados da década de 70 configurava-se dentro de tentativas oficiais de racionalizar e implementar políticas sociais que legitimassem o Estado Militar em crise de sustentação política, encarregado de promover um projeto de desenvolvimento económico caracterizado pela concentração de riquezas e poder.

Uma vez apontadas as características pol tico-ideológicas da emergência de programas para as crianças, agora entendidas como grupo materno-infantil, delineiam-se outras indagações: as recentes mudanças na conjuntura nacional, caracterizadas por uma transição negociada entre as camadas dominantes, podem garantir a elaboração de propostas para o grupo que digam respeito às suas condições concretas

9 COSTA, N. R. Lutas Urbanas e Saúde Pública. Petrópolis, Vozes, 1985.

10 NOVAES, M. H. A Puericultura em Questão. Dissertação de Mestrado da Faculdade de Medicina da USP, São Paulo, 1979.

11 MINISTÉRIO DA SAÚDE. Programa Materno-lnfantil. Brasília, 1975. 
de vida? Os programas de saúde que se apresentaram a partir de meados da década de 80 foram elaborados com a participação dos selares da população para os quais são dirigidos? Representaram (e representam) uma opção política no sentido de garantir sua execução, a transparência de suas decisões e o controle desta execução pelos próprios interessados?

\section{CRIANÇA OU MENOR}

Concluindo, é importante relacionar dois momentos históricos que apresentam um ponto em comum extremamente dramático.

Se ao longo do período colonial não existia a criança, mas o filho, fosse o filho primeiro, herdeiro da propriedade, ou os demais, legítimos e/ou bastardos, que se enquadravam de maneira mais ou menos eficiente nos amplos limites do latifúndio, inclusive na sua extensão citadina, qual o destino daqueles que não eram cobertos por esses limites?

Não se trata de um acaso histórico a instituição de "roda" como destino de quem não era filho da propriedade.

Se com o desenvolvimento económico, com as mudanças sofridas pela sociedade brasileira o "filho da propriedade foi transformado em criança, o que aconteceu com o filho da "roda"?

Incapaz de "domesticar" ou atender via saúde ou educação os “filhos da roda”, não terá a sociedade criado novamente dois tipos de concepção em relação à criança? De um lado a criança e de outro lado o menor?

Não será o "menor" o fruto deste descaso histórico com a criança?

Assim sendo, considera-se que, ao lado de uma reflexão ou de um conjunto de problemas que possam atribuir-se à "criança" a partir de uma construção descritiva ou analítica de seu crescimonto e desenvolvimento, através de áreas pedagógicas, pediátrica, psicológica, outros serão os problemas a serem lançados para O “menor”.

Em primeiro lugar cabe destacar uma dimensão política, que diz respeito às formas de manipulação do “menor”, Poloícia, abrigo, serviços de saúde, assistência social referem-se a práticas criadas para socializar o "menor" que escapa ao controle da família e, sobre essas práticas, teorias são produzidas e políticas instituídas.

Em segundo lugar estaria a dimensão sociológica, que deveria focalizar as relações sociais criadas a partir da legitimidade que têm os distintos alores que manipulam o abrigo/assistência/tutela do menor, e das respostas que este alor, "a criança menor", tem em relação a elas. Neste caso, aluam outros alores: a policia e os grupos de menores já crescidos que, como espaço, têm as cidades brasileiras para navegar.

Desta forma, se houve em nossa sociedade um desenvolvimento das práticas e do pensamento sobre a criança com ações que propugnam a idéia de cuidado e atenção para um processo de desenvolvimento e crescimento próximo de uma normalidade cientificamente determinada, ou de práticas que colocam a idéia de liberdade ou de estimulo às potencialidades, práticas que se manifestam desde o aumento do consumo pediátrico, pedagógico e psicológico à produção teórica sobre esse processo, o outro lado, o "menor", não tem sido pensado independente da reflexão sobre marginalidade/instituicão.

Caberia levantar, portanto, que, além das reflexões sobre a "criança" ou sobre o "menor" marginal/institucionalizado, uma face oculta e oposta deve suscitar o principio para uma investigação mais puramente sociológica. Trata-se da idéia do desenvolvimento do menor que se constitui através da violação, através de relações apostas ao cuidado/preservação.

Esta face, mais dificilmente digerida, apontaria para raízes violentas de nossa sociedade, e para a busca de um quadro que não necessariamente buscaria a positividade, ou ausência de um quadro "normal" de crescimento/desenvolvimento, mas para a constituição do adulto através das relações de violência, de privação, de afirmação de uma autonomia dentro de um terreno de relações sociais de exclusão, extermínio e resistência. Quadro este que abre perspectiva para novos paradigmas de investigação sobre o problema menor e a constituição de relações sociais em torno de sua trajetória. 